\title{
Performance Analysis of a Hybrid Solar-Geothermal Power Plant in Northern Chile
}

\author{
Ignacio Mir ${ }^{1}$, Rodrigo Escobar ${ }^{1}{ }^{*}$, Julio Vergara $^{1}$, Julio Bertrand ${ }^{2}$ \\ ${ }^{1}$ Departamento de Ingeniería Mecánica y Metalúrgica, Pontificia Universidad Católica de Chile, Santiago, \\ Chile. \\ ${ }^{2}$ Empresa Nacional del Petróleo, ENA, Santiago, Chile \\ * Corresponding author. Tel: +562 3545478, Fax: +562 3545828, E-mail: rescobar@ing.puc.cl
}

\begin{abstract}
Chile has introduced sustainability goals in its electricity law in response to increased environmental awareness and the need to achieve higher levels of energy security. In northern Chile, the Atacama Desert has a large available surface with high radiation level, while the tectonic activity along the entire country testifies an ample yet unexploited geothermal resource. The novel concept of hybridizing a geothermal power plant with solar energy assistance is presented here for the particular conditions of Northern Chile. A thermodynamic model is developed to estimate the energy production in a hybrid power plant for two different configurations of solar resource use: adding peak power for a constant geothermal output, and saving geothermal resources for a constant power output. The thermodynamic model considers a single-flash geothermal plant with the addition of solar heat from a parabolic trough field. The solar heat is used to produce superheated steam and to produce additional saturated steam from the separator whenever possible. Results indicate that the energy produced by a geothermal well can be increased up to $11.6 \%$ and achieve savings of up to $10.3 \%$ in the use of geothermal resources by adding solar assistance when using the single flash geothermal technology. Moreover, the optimal mass flow rate of the geothermal plant is decreased when adding solar assistance. It is recommended to exploit solar energy together with geothermal energy wherever possible, to take advantage of each other's strengths and mutually eliminate weaknesses.
\end{abstract}

Keywords: Concentrated solar power, Geothermal Power Plant, Hybrid, Chile

\section{Introduction}

Chile exhibits a large diversity of geographical features and climates which has a great impact on the availability of renewable energy sources and their proper assessment. The country has limited energy resources apart from hydroelectric capacity, with a negligible internal fossil fuel production, thus relies on fuel imports to meet its growing energy demand. Renewable energy sources in use by the country comprise only hydroelectricity and wood-based biomass, which combined, only account for $24 \%$ of primary energy consumption as of 2008, while non-renewable fossil fuels account for the remaining 76\%. Primary energy (Ep) consumption has increased at a yearly rate of $5 \%$, and it is projected to continue doing so as the country further develops [1]. The mechanism that is currently operating in Chile consists in the application of a mandatory renewable energy quota requiring a minimum of $5 \%$ of electricity generation starting in 2010 must come from renewable energy sources, excluding large scale hydroelectricity, with a gradual increase of the quota to reach a $10 \%$ in the electricity generation mix by 2024 [2]. Given the local distribution of renewable energy sources, northern Chile displays no potential whatsoever for hydroelectricity and biomass since the area is the driest desert in the world. Although there is considerable potential for solar and geothermal energy, none of them is currently contributing to the energy mix, mostly due to the high uncertainty and cost of geothermal exploration and the lack of proper solar radiation databases [3]. Here we propose to integrate both energy sources in a hybrid concept, in order to take advantage of each other strengths and eliminate possible weaknesses. Geothermal resources tend to supply saturated steam and thus are limited in temperature and efficiency, while solar resource is available in daily cycles unless thermal energy storage is used. The goal of the present study is to find the configuration of an hybrid power plant that result in the best combination of solar thermal and geothermal power cycles. The concept of harvesting 
solar and geothermal energy together has been proposed in the literature [4, 5] although in those cases the solar energy is used to increase the dryness fraction of the geothermal brine. This approach has been demonstrated as flawed since it makes a less efficient use of the highexergy, high-cost solar heat. It has been showed previously that the best combination is to utilize the solar energy to increase the temperature of the geothermal fluid by superheating it, with the use of binary cycles also been proposed as a useful alternative for using low-enthalpy geothermal sources [6, 7]. In what follows, we will first describe a power plant configuration with an only-geothermal plant as base case, and then a model of hybridized plant for comparison purposes, aiming to improve the cycle's thermal efficiency and to create synergies between the two energy sources. The results will compare the total electricity produced in a period, and the consumption of geothermal fluid which is related to well depletion.

\section{Power plant models}

This section presents the plant models under study, focusing on the thermodynamic cycles. First a base case of geothermal-only plant is presented, and then the hybrid Solar-geothermal plant is described.

\subsection{Geothermal base cycle}

The geothermal power plant model considered for this study consists on a single production well and the basic components of a single flash power plant: a steam separator, turbine, condenser, and re-injection well as shown in Fig. 1. We consider a demonstration plant which is fed by a single well reaching a nominal power of 3.974 MW.
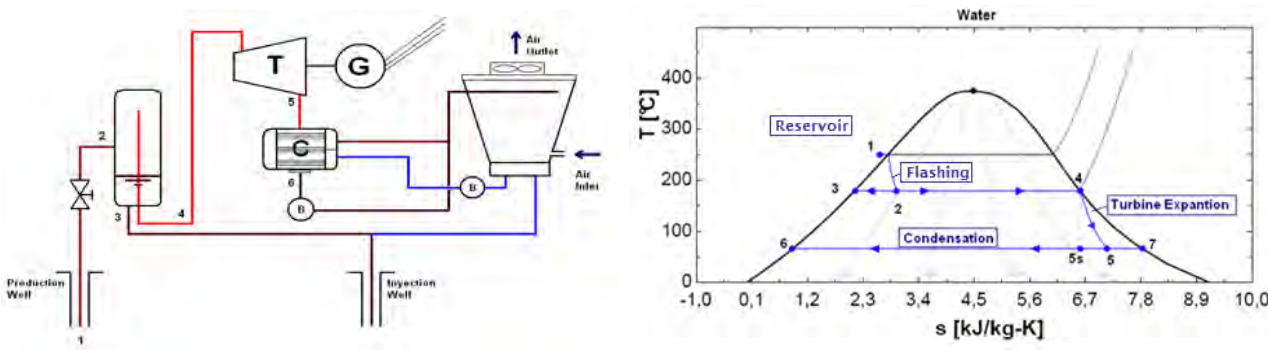

Fig. 1: Single flash plant and T-s diagram.

Numbers in the plant schematic match those from the T-s diagram. The letters T, C, and G stand for turbine, condenser and generator respectively. The conditions at the reservoir are considered to remain constant, while the behavior of the production well is be assumed to follow the productivity curve given by the polynomial expression that relates the mass flow rate with the wellhead pressure [6]:

$$
\dot{m}=44.333-0.3363 \times P-0.1357 \cdot P^{2}
$$

This fixes the conditions at the cycle beginning. The well head pressure is selected by optimizing the output power as $\operatorname{Max}\left\{x_{2} \times\left(h_{5}-h_{6}\right)\right\}$, where the index numbers matches those on Fig. 1; therefore, by fixing the working pressure of the condenser, i.e. the pressure at the turbine's outlet, the geothermal power cycle is assumed completely determined. The condenser pressure used here is $0.01234 \mathrm{MPa}$, equivalent to a condensing temperature of $50^{\circ} \mathrm{C}$. For all cases, it is assumed that the reservoir is at a constant temperature of $250^{\circ} \mathrm{C}$. The steam fraction after the separator is given by $\dot{m}_{\text {steam }}=x_{2} \times \dot{m}_{\text {total }}$, and the specific power from the turbine is $w_{t}=h_{4}-h_{5}$, where $h_{5}$ stands for the enthalpy at the turbine outlet. If we 
assume an ideal turbine, then we will have the ideal work produced by the turbine. Thus, we define the isentropic efficiency as the fraction between the real work produced by the turbine and the ideal work at the same conditions, considering $h_{5 s}$ as the isentropic enthalpy at the turbine outlet:

$$
\eta_{t}=\frac{h_{4}-h_{5}}{h_{4}-h_{5 s}}
$$

The turbine efficiency is affected by the moisture level present in the steam during expansion. The larger the moisture present, the smaller is the turbine efficiency. This effect can be quantified using the Baumann's rule [8] which proposes that a 1\% increase in moisture causes roughly a $1 \%$ drop in turbine efficiency. Adopting this rule, the isentropic efficiency is given by:

$$
\eta_{t}=\eta_{t d} \times \frac{x_{4}+x_{5}}{2}
$$

Where $\eta_{t d}$ represents the turbine isentropic efficiency working with dry steam, $x_{4}$ is the dryness fraction at the turbine inlet, assumed to be equal to one, and $x_{5}$ is the dryness fraction at the turbine outlet. It is assumed that the turbine isentropic efficiency for dry steam is constant and equal to $85 \%$. The dryness fraction at the turbine outlet is calculated as:

$$
x_{5}=\frac{h_{5}-h_{6}}{h_{7}-h_{6}}
$$

Where $h_{6}$ and $h_{7}$ are the enthalpies of saturated liquid and saturated vapor at the condenser pressure. As the dryness fraction at the turbine outlet depends on the isentropic efficiency, Eqs. (1) to (3) need to be solved simultaneously in order to determinate $h_{5}$ and therefore the specific power produced by the turbine. The mechanical power produced by the turbine is then calculated as $\dot{W}_{t}=\dot{m}_{\text {steam }}{ }^{*} w_{t}$. The model considers that the generator efficiency is equal to 1 , and that the parasitic loads are negligible. Finally, the heat rejected by the condenser after the turbine expansion is given by:

$$
\dot{Q}_{\text {cond }}=\dot{m}_{\text {steam }} *\left(h_{5}-h_{6}\right)
$$

With this the geothermal base cycle is defined and can be solved in order to obtain the steadystate power production.

\subsection{Solar Field Modeling.}

The solar field for the hybrid power plant is composed of parabolic trough collectors. The solar field sizing considers monthly means of solar radiation and the thermal energy demand. This demand depends on the characteristic of the thermodynamic cycle for each hybrid power plant configuration, depending on steam mass flow rate and the desired maximum temperature of the superheated steam being produced with solar heat. Once the thermal energy demand is determined, the field is sized for satisfying the demand by using a day modeled with the annual average radiation, which in northern Chile is within $20 \%$ of the annual maximum value. The sizing procedure includes an energy balance in which the collector area is determined as to ensure that the maximum desired temperature of the superheated steam is met after it passes through the heat exchanger system. The model utilizes Therminol VP1 as the solar field heat transfer fluid (HTF); its properties are obtained from the manufacturer, assuming a maximum working temperature of $400{ }^{\circ} \mathrm{C}$ [9]. Heat losses in the 
receiver element are modeled based on correlations proposed by NREL [10] as a function of the temperature difference between HTF and the environment:

$$
\dot{Q}_{\text {loss }}=0.41 \cdot \Delta T+1.21 \cdot 10^{-8} \cdot \Delta T^{4}
$$

A counter flow heat exchanger is used, considering an effectiveness of 95\%. The energy balance in the heat exchanger is given by:

$$
\eta_{H X} \times \dot{m}_{H T F} \times C p_{V P 1} \times\left(T_{d}-T_{\sigma}\right)=\dot{m}_{A B} \times C p_{A B} \times\left(T_{a}-T_{b}\right)
$$

Where $\eta_{H X}$ is the heat exchanger effectiveness, $\dot{m}_{H T F}$ is the HTF mass flow rate, $C_{p} V P 1$ is the HTF heat capacity, $T_{D}$ is the hot HTF temperature, $T_{C}$ is the cold HTF temperature, $\dot{m}_{A B}$ is the water or steam mass flow rate, $C p_{A B}$ is the steam heat capacity, $T_{A}$ is the sold steam temperature, and $T_{B}$ is the hot steam temperature. Once the parabolic trough array is sized, it is possible to simulate the operating conditions for each hour of the year by using hourly solar radiation data. The solar field works in a similar way for all cases, varying the mass flow rate of the HTF to keep the outlet temperature constant at the design temperature independent of the actual radiation value. If the solar radiation in a given hour is higher than the design radiation, then it will have a HTF mass flow rate greater than the designed and vice versa. When solar energy exceeds the design value, the extra energy is used to increase the brine dryness factor.

\subsection{Hybrid Power Plant}

The hybrid Solar-Geothermal power plant consists of a geothermal power plant with assistance from a solar field. Two main scenarios for power production are used; the first aims to produce as much energy as possible without altering the basic operation of the geothermal component of the system, keeping the geothermal optimal mass flow rate from the reservoir fixed and producing extra power as function of solar radiation availability. The second scenario intends to keep the power production constant by reducing the geothermal mass flow rate while supplying extra heat from the solar field. The basic premise here is that saving geothermal fluid could result in extended well and reservoir lifetime, and as a result, decrease make up drilling costs without compromising the energy output rate. The input data are the geothermal well production curve and the solar radiation available (as in Eq. 1), and the prevailing climatic conditions at the chosen plant location. The solar radiation is obtained from pyranometer data available for the general area of Calama $\left(22^{\circ} 2 \mathrm{~S}, 68^{\circ} 5 \mathrm{~W}\right)$.
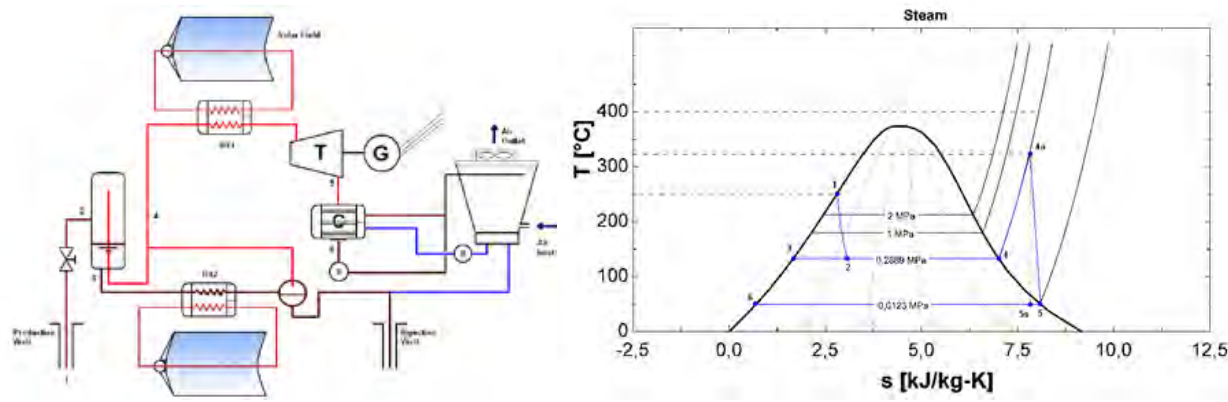

Fig. 2: Single flash Solar-Geothermal plant and T-s diagram.

\subsubsection{Hybrid Solar-Geothermal, Scenario 1}

A single-flash geothermal power plant is considered, with solar superheating after the separator. This scenario aims to increase production of the plant during the daylight hours 
when electricity demand is higher and radiation is available. The geothermal well is kept working at constant mass flow rate, while solar thermal energy is added to increase output power. In this case, a superheating temperature of $320.8^{\circ} \mathrm{C}$ is reached according with the thermodynamic conditions. With this temperature, using the radiation data for Calama and assuming an environment temperature of $15^{\circ} \mathrm{C}$, a solar field total aperture area of $4760 \mathrm{~m}^{2}$ is obtained. If the solar radiation is higher than the design radiation (which is used to size the solar field as previously explained), then the excess is used to evaporate part of the saturated liquid stream from the separator and thus increase the main steam flow. If the solar radiation is lower than the design radiation, point $4 \mathrm{a}$ in the $\mathrm{T}$-s diagram does not reach the maximum temperature, but it is instead located closer to point 4. In the limit with no solar radiation available, points 4 and 4a merge and fall in the saturated steam line. When point 4a is below the maximum temperature, expansion within the turbine will occur in two stages; the first is an expansion of superheated steam where the turbine isentropic efficiency is not affected by moisture, and a second stage where the expansion falls into the saturated steam zone, with moisture causing the turbine efficiency to be reduced according to the Baumann's rule [8].

\subsubsection{Hybrid Solar-Geothermal, Scenario 2}

The second scenario aims to study a possible configuration that could reduce geothermal steam consumption and thus extend both well and reservoir life cycle. This can be achieved by replacing geothermal energy by solar energy when it is available, reducing the mass flow rate of geothermal fluid from the reservoir, and then using solar energy to compensate for the missing power by keeping the output power equal to the one obtained in the base scenario. The solar field sizing is done by fixing the turbine output at a value of $3.974 \mathrm{MW}$ (equal to the base case, geothermal-only power plant), and then assuming that the design solar radiation is completely available. For this power output, the production curve of Eq. (1) indicates that the lowest extraction pressure is $0.9022 \mathrm{MPa}$, which results in a steam mass flow rate of 30.25 $\mathrm{kg} / \mathrm{s}$ from the well, yielding $5.1 \mathrm{~kg} / \mathrm{s}$ of saturated steam after the separator. The maximum steam temperature is limited to $400{ }^{\circ} \mathrm{C}$, due to the HTF working range. This requires a power of $2505 \mathrm{~kW}$ in the heat exchanger number one (HX1, as in Fig. 3) and then a reheating step to take the steam back to $400{ }^{\circ} \mathrm{C}$ in the $\mathrm{HX} 2$ in order to deliver the $533.7 \mathrm{~kW}$ that are needed to reach the base case output power. This gives a total solar contribution of $3038 \mathrm{~kW}$ for the design conditions, resulting in a solar field collection area of $3685 \mathrm{~m}^{2}$ in this scenario.

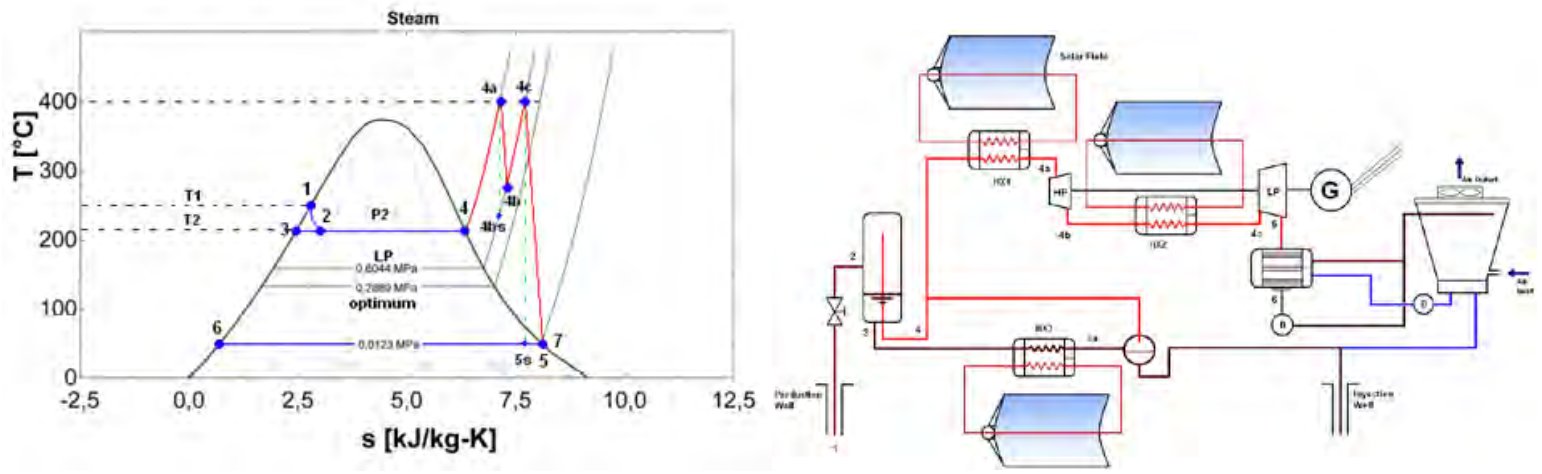

Fig. 3: Single flash Solar-Geothermal plant with reheating and T-s diagram.

An iterative process for the geothermal fluid mass flow rate is performed in order to determinate the thermodynamic states in the power plant model in an hourly basis during a 1year period. The starting point is a given mass flow rate, which is reduced according to the available solar radiation. A decrease in the well mass flow rate results in a pressure increase at the separator inlet, thus allowing the superheating pressure value to be established. Solving 
for the base case output power gives the amount of reheating needed. Again, the procedure is repeated in an hourly basis for the entire 1-year period.

\section{Results}

The main results obtained in this study are the hourly energy production of the base geothermal-only and the two scenarios of the Solar-Geothermal hybrid power plant, which can be integrated in a 1-year period to obtain the annual energy production of each plant.

\subsection{Base Case}

The first results correspond to the base case, a geothermal-only plant. By solving the equations that represent the thermodynamic cycle in Fig. 2 for a geothermal power plant, it is possible to obtain the optimum mass flow rate from the reservoir and the pressure at which the separator operates, thus achieving the maximum possible power output. The output power is $3974 \mathrm{~kW}$, the total mass flow rate is $42.22 \mathrm{~kg} / \mathrm{s}$, the separator pressure is $0.2897 \mathrm{MPa}$, the energy produced for the entire year assuming a plant factor of $100 \%$ is $34.81 \mathrm{GWh}$, and the amount of extracted geothermal fluid in a year is 1331500 Tons, parameters which are established as the base case for our comparisons, corresponding to a plant that operates with a single well for a 3.974 MW power output.

\subsection{Hybrid Solar-Geothermal, Scenario 1: Increased production}

Even though the Chilean Desert offers a large number of clear days throughout the year, the daily radiation is subject to hourly variability as can be seen in days $1,2,5$, and 9 of the 10day sequence in Fig. 4. The different peaks in power output allow the plant to produce as much as $5.5 \mathrm{MW}$, an increase of more than $30 \%$ from the base power output. It can be seen that this scenario results in an annual increase of $11.36 \%$ on the total energy produced by the plant respect to the base case. An additional advantage of this configuration is that there is no need to regulate the mass flow rate of geothermal fluid from the reservoir, thus resulting in a much simpler plant operation scheme. However, the daily output power profile, where this scenario displays daily power production peaks make the power production variable and not easy to predict, which constitutes a disadvantage in terms of power dispatchability. Even though the difference between daily maximum and minimum varies only around $20 \%$, the power curve is not as attractive as a flat curve. A positive point for these power production profiles is that, in general, the output power peak takes place during peak demand hours, thus resulting in highest spot prices that make this option attractive. The abnormality shown February is due to the altiplanic winter effect, where cloudy periods are present caused by the Amazonia wet season.

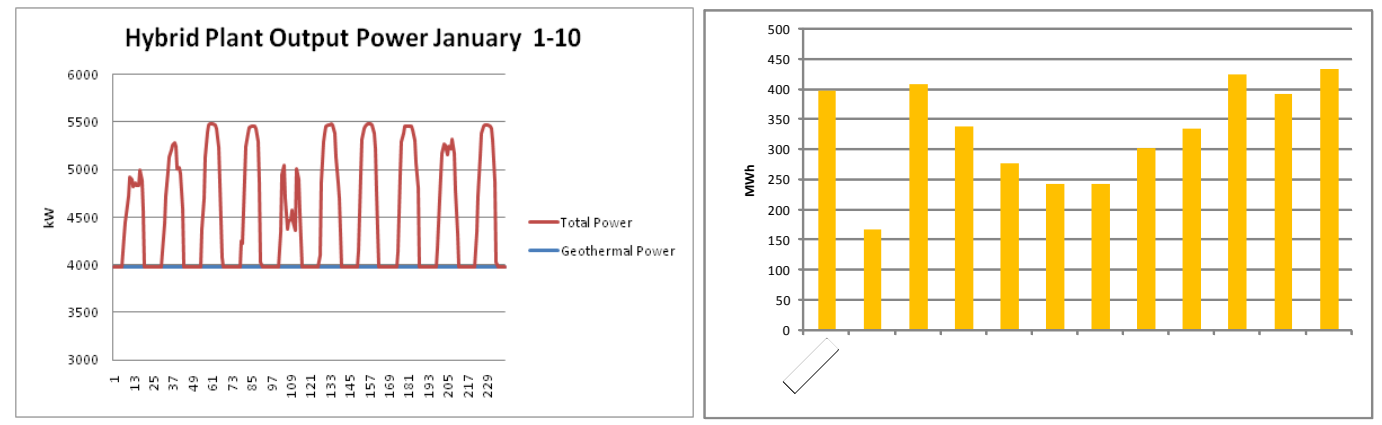

Fig. 4: Daily output power and monthly energy added, Solar-Geothermal plant Scenario 1. 


\subsection{Hybrid Solar-Geothermal, Scenario 2: Geothermal fluid savings}

In this scenario the goal is to produce the same amount of energy as in the base case, by reducing the mass flow rate of geothermal fluid according to the availability of solar radiation, thus using solar heat to compensate for the reduced steam flow while maintaining the power output constant. Fig. 5 shows the power production profile for the same 10-day sequence as in Fig. 4, this time for the conditions corresponding to Scenario 2. The power production remains flat at a 3.974 MW value. The geothermal contribution, however, decreases as solar radiation becomes available. A significant reduction of $10.36 \%$ in geothermal fluid mass flow rate can be achieved for this particular conditions, which might translate into longer well and reservoir life, thus reducing the cost of exploring and drilling for new wells to replace those already depleted. An additional benefit is given by the flat power production profile, which makes this plant configuration attractive for sales contracts as is able to supply base load to the Chilean grid. This plant configuration also requires the smallest solar field sizes, due to the reduced solar heat required and the improved thermodynamic efficiency obtained in this scenario. The reduction of mass flow rate from the producing well implies a higher working pressure as per Eq. (1); adding this to the increased steam temperature achieved by the solarsuperheated steam increases the efficiency of the thermodynamic cycle. Fig. 5 also displays the monthly total energy produced during a 1-year period. It can be seen that the solar contribution in this scenario is larger than that of scenario 1 , thus effectively operating with an increased solar fraction.

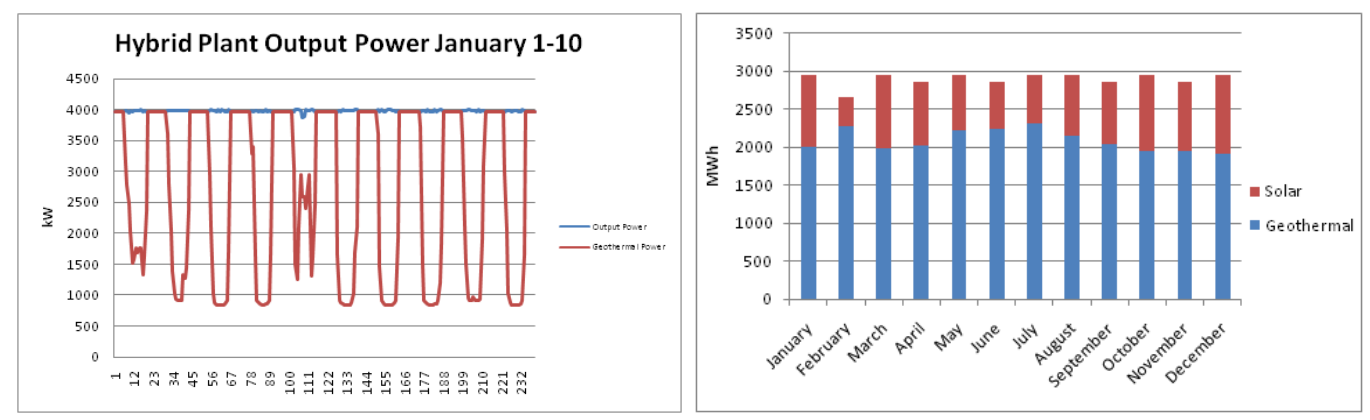

\section{Conclusions}

Fig. 5: Daily output power produced by the Solar-Geothermal plant, Scenario 2.

Chile faces several energy challenges as a country which is a net energy importer. The country exhibits ample potential for both solar and geothermal energy. Considering the variability of solar energy and the limitations that the use of saturated steam poses to geothermal energy, it is proposed to combine both energy sources into an hybrid power plant concept, with the general goal of taking advantage of each other strengths and mitigate their weaknesses. The hybrid Solar-Geothermal power plant models being presented consider a single flash geothermal plant with the addition of a parabolic trough collector solar field used for steam superheating. In this way the hybrid plant increases its maximum operating temperature and operates with superheated steam expansion in the turbine, as opposed to saturated steam expansion in the original, geothermal-only plant. Simulations of the plant operation in 1-year periods are performed based on hourly databases of available solar radiation for Northern Chile. Two different scenarios are proposed. The first allows the solar heat to increase the power production from the base case geothermal plant, while the second maintains a constant power output, instead utilizing the solar heat to reduce the geothermal fluid mass flow rate. It is found by the authors that the first scenario allows producing as much as $12 \%$ more energy than the base case due to the use of solar energy, producing an output power profile with daily peaks following the daily solar radiation availability. These power production peaks coincide with the peak energy demand hours, thus allowing the sale 
of electricity at a larger price in the spot market. The main advantage of this generation scheme is the simplicity of its operation, where geothermal components operate the same way they do in a conventional geothermal power plant, allowing the solar radiation to add a contribution whenever available. The second scenario intends to use the available solar radiation as a way to save geothermal fluid mass flow rate. The basic premise is that reducing the well mass flow can result in an extended well and reservoir life, thus saving on exploration and perforation costs. This scenario produces a flat power output profile and therefore the same amount of energy produced than the geothermal-only base case, with lower geothermal fluid utilization. Reductions of more than $10 \%$ of geothermal fluid utilization were achieved when comparing to the base case. The operation of a power plant under this scenario requires constant monitoring of the well mass flow rate according to the availability of thermal energy coming from the solar field, which in practice is complex and has never been done before. It is also not known at the present time if the geothermal reservoir can be managed in such a way. The geothermal solar hybrid concept represents an interesting prospect for the Chilean electricity market, with the potential of providing base load energy with a high capacity factor from emissions-free and environmentally friendly sources. Further analyses are being performed for developing an economic model and assess in more detail the feasibility of this concept

\section{Acknowledgements}

Proyect FONDECYT 1095166 provided the computational platforms and simulation software, while Project FONDEF D08i1097 provided the solar radiation data.

\section{References}

[1] Comisión Nacional de Energía, CNE (2010). Balance Nacional Enegético 2008. Last accessed at http://www.cne.cl/cnewww/opencms/06_Estadisticas/Balances_Energ.html on August 13, 2010.

[2] Ministerio de Economía. Ley general de servicios eléctricos, Decreto con fuerza de ley n4, Art. único Nº 2, D.O. 01.04.2008. Santiago, February 2007.

[3] Ortega, A., Escobar, R., Colle, S., Abreu, S. (2010). The State of Solar Energy Resource Assessment in Chile. Renewable Energy, 35, 11, 2514-2524.

[4] Handal, S., Alvarenga, Y., \& Recinos, M. (2008). Solar Steam Booster in the Ahuachapán Geothermal Field. El Salvador.

[5] Lentz, \& Almaza. (2003). Parabolic troughs to increase the geothermal wells flow enthalpy. Mexico.

[6] DiPippo, R. (2008). Geothermal Power Plants; Principles, Applications, Case Studies and Enviromental Impact, Second Edition. London: Elsevier.

[7] Tester, J. et al, Massachusetts Institute of Technology (MIT) (2006). The future of geothermal Energy. Retrieved Jan, 2010. Last accessed on August 13, 2010 at: http://geothermal.inel.gov/publications/future_of_geothermal_energy.pdf.

[8] Leyzerovich, A. (2005). Wet-Steam Turbines for Nuclear Power Plants. New York: PennWell.

[9] Therminol. (2009). Therminol. Retrieved 2009, from www.therminol.com

[10]National Renewable Energy Laboratory NREL. (2009). TroughNet, Parabolic Trough Solar Field Technology Retrieved 2009, from: http://www.nrel.gov/csp/troughnet/solar_field.html. 